Volume: 1, Issue: 2, June 2016, Pages: 49-53, DOI: http://dx.doi.org/10.19082/ah49

\title{
SIMULTANEOUS FRACTURE OF THE HOOK OF THE HAMATE AND FOURTH CARPOMETACARPAL JOINT: CASE REPORT
}

\author{
Behrang Rezvani Kakhki ${ }^{1}$, Seyyed Reza Ahmadi ${ }^{2}$, Morteza Talebi Deloei ${ }^{1}$, Hosein Zakeri ${ }^{1}$, Saeideh Anvari
} Ardakani $^{3}$

1: M.D., Assistant Professor, Department of Emergency Medicine, Faculty of Medicine, Mashhad University of Medical Sciences, Mashhad, Iran

2: M.D., Resident of Emergency Medicine, Department of Emergency Medicine, Faculty of Medicine, Mashhad University of Medical Sciences, Mashhad, Iran

3: M.D., Resident of Neurology, Department of Neurology, Faculty of Medicine, Mashhad University of Medical Sciences, Mashhad, Iran

\section{TYPE OF ARTICLE: CASE REPORT}

\begin{abstract}
Introduction: Evidence of a fourth carpometacarpal joint dislocation and hamate fracture is rare, which may be due to its difficult and sometimes missed diagnosis based on routine X-rays. A simultaneous fracture of the hamate and carpometacarpal joint dislocation in the same hand is extremely rare. We report a case of a combination of a fourth carpometacarpal joint dislocation and a fracture of the hook of the hamate detected by computer tomography $(\mathrm{CT})$ imaging.

Case Presentation: The patient was a 32-year-old right-hand-dominant man, with a chief complaint of righthand pain, especially in the fourth and fifth fingers, which began immediately after punching a handle of an armchair. On physical examination, there was a deformity and tenderness with reduced range of movement (ROM) on the fourth metacarpal. Radiographs showed a dislocation of the fourth carpometacarpal joint and a suspicious fracture in the hook part of the hamate. Then, the patient underwent a CT image that indicated a dislocation of the fourth carpometacarpal joint and a fracture in the hook of the hamate. An open reduction and internal fixation (ORIF) was done, and the wrist and hand were immobilised for six weeks. At three months' follow-up, the patient had normal strength in his hand, and he was asymptomatic.

Conclusion: Hamate fracture is often missed on initial presentation and initial X-ray, which emphasises the need for compulsive diagnostic evaluation such as CT imaging and careful follow-up. In fact, when there is a tenderness, and a reduced ROM on the base of fourth carpometacarpal joints, CT is helpful in a more accurate diagnosis.
\end{abstract}

KEYWORDS: Fracture, hamate, Carpometacarpal joint, Diagnosis

\section{INTRODUCTION}

Dislocation of the fourth carpometacarpal joints is an unusual injury, which usually results from forces acting directly on the joints $(1,2)$. Hamate fractures are also uncommon fractures and are among the least carpal fractures reported in the literature with the incidence of $2 \%$ of all carpal fractures (3). The evidence of the hook of hamate fractures is rarer, which may be due to its difficult and sometimes miss diagnosis based on routine X-rays (4). Nevertheless, simultaneous fracture of the hamate and carpometacarpal joint dislocation in the same hand is extremely rare (5-8). We report a case of a combination of a fourth carpometacarpal joint dislocation and a fracture of the hook of the hamate.

\section{Correspondence:}

Dr. Seyyed Reza Ahmadi, Department of Emergency Medicine, Faculty of Medicine, Mashhad University of Medical Sciences, Mashhad, Iran. Tel: +98.5138525312, Fax:+98.5138525312, E-mail: ahmadi_ums@yahoo.com Received: January, 17, 2016, Accepted: March 02, 2016, Published: June 2016

iThenticate screening: January, 24, 2016, English editing: March 12, 2016, Quality control: March 30, 2016

(C) 2016 The Authors. This is an open access article under the terms of the Creative Commons Attribution-NonCommercialNoDerivs License, which permits use and distribution in any medium, provided the original work is properly cited, the use is non-commercial and no modifications or adaptations are made. 


\section{CASE PRESENTATION}

\subsection{Patient Information}

The patient was a 32-year-old right-hand-dominant man, $173 \mathrm{~cm}$ in tall, weighing $76 \mathrm{~kg}$. His chief complaint was right-hand pain, especially in the fourth and fifth fingers, which began immediately after punching am armchair handle. He came to our emergency department 1 hour later. There was no significant point in his past medical history.

\subsection{Clinical Findings}

On physical examination, there was a deformity without any swelling, ecchymosis, or open wound, and a dorsoulnar deviation of 10 degrees on the fourth metacarpal in inspection (Figure 1). Also, there was a point tenderness over the base of the fourth metacarpal and a reduced range of movement in all directions. A palmar pain aggravation was observed with flexion of the fourth and fifth digits. However, there was weakness of power grip, but there was no nerve damage in the hand.

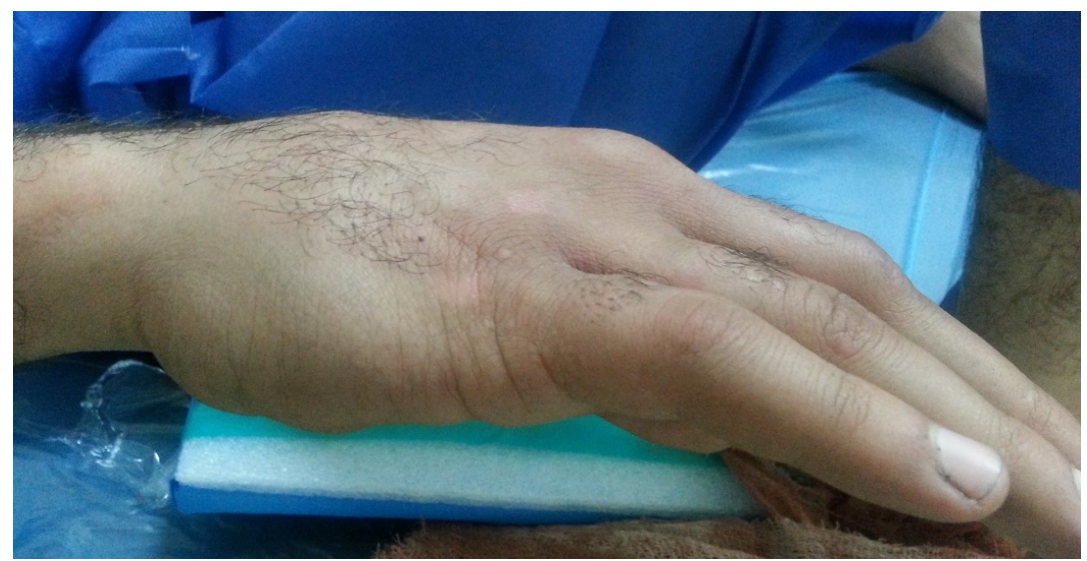

Figure 1. In the inspection, there was a deformity and a dorsoulnar deviation of 10 degrees on the fourth metacarpal.

\subsection{Diagnostic Assessment}

There was no evidence of fracture dislocation of the wrist, but radiographs showed a dislocation of the fourth carpometacarpal joint and a suspicious fracture in the hook part of hamate (Figure 2). A lateral view confirmed the fourth carpometacarpal joint dislocation (Figure 2). A computer tomography (CT) image was performed for a more acute evaluation, which indicated a dislocation of the fourth carpometacarpal joint and a fracture in the hook of the hamate (Figure 3).
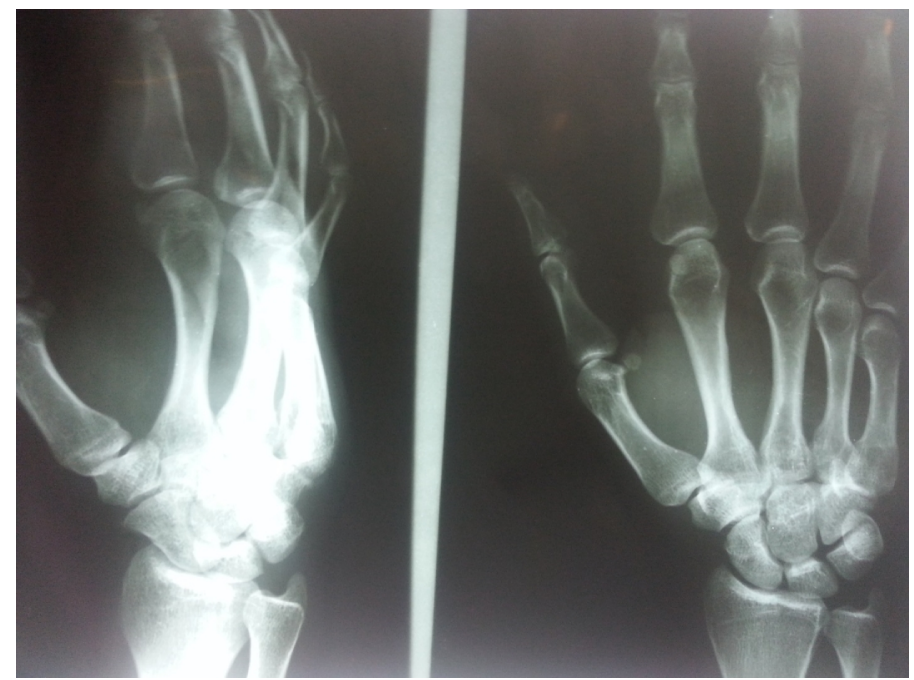

Figure 2. Radiography showed a dislocation of the fourth carpometacarpal joint and a suspicious fracture in the hook part of the hamate. A lateral view confirmed the fourth carpometacarpal joint dislocation. 


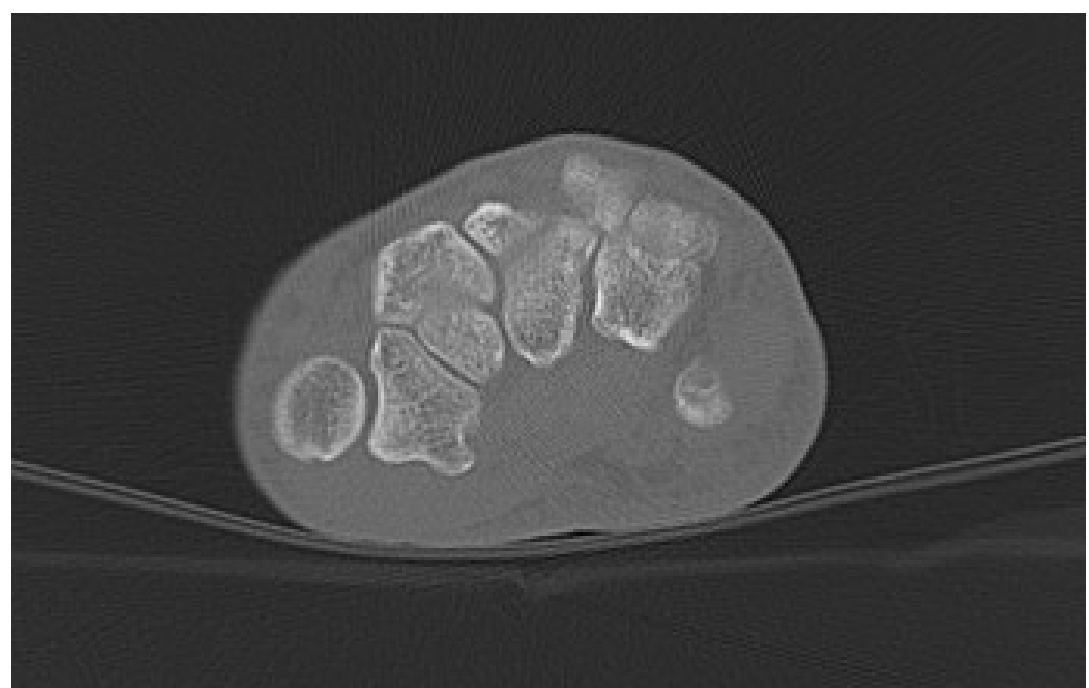

Figure 3. Computer tomography image showed a dislocation of the fourth carpometacarpal joint and a fracture in the hook of the hamate.

\subsection{Therapeutic Intervention}

At first, a close reduction was done, and after one day an open reduction and internal fixation (ORIF) were done through a dorsal longitudinal incision over the carpometacarpal joint using Kirschner wires, one through the bases of the ulnar three metacarpals, the other through the hamate and capitate bones (Figure 3). The wrist and hand were immobilised for six weeks.

\subsection{Follow-up and Outcomes}

Six weeks after surgery, the Kirschner wires were removed; on follow-up eight weeks after the operation, his fourth little finger was in perfect alignment and he had attained a full range of motion. In 8 weeks' follow-up, the patient had a normal strength in his hand, and he was asymptomatic. X-rays showed the fifth metacarpal in a corrected position. The power grip was improving and near normal.

\section{DISCUSSION}

Wrist injuries are among the most common and emergent orthopaedic cases. Diagnosing and treating these injuries are difficult and are not often detected due to the complex structure of the wrist (9). Hamate fractures are uncommon and usually occur after clenched fist trauma $(10,11)$. Hamate fractures are divided into two groups regarding hook (such as this case report) or body involvement. However, it is notable that the hook is involved in most cases. Hook fracture is usually caused by direct pressure or falling on the ground while the wrist is dorsiflexed (11, 12). However, this type of fracture, particularly if accompanied with carpometacarpal (CMC) dislocation, is rare and makes the correct diagnosis more difficult (11). The position is effective for applying force and how to transfer it to determine the fracture pattern (13). In a clinical examination of such injuries, swelling, ecchymosis, and the pain diffused in the ulnar aspect are usually reported. If the patient feels pain in a direct touch of hypothenar eminence, damage to the ulnar nerve should be examined. In previous studies, damages to the ulnar nerve have been reported in both body and hook hamate fracture (14-16). Delay in detecting these lesions can lead to fibrous and the progressive loss of hand strength (17). Routine radiological investigations in these types of injuries include posterior anterior (PA), lateral, and oblique radiographs. If these measures fail to recognise, a posterior-anterior radiograph and a 30-degree pronated view and ultimately CT scan can help us $(11,15, \& 18)$. In previous researche, using simple radiography in the timely diagnosis of these fractures is questioned because, in accordance with flexor and extensor tendon surgery, the fracture pattern can change in the case of delay in diagnosis (11, 15). Bora et al. proposed a 30-degree pronated view in their study to check for the combined fourth and fifth CMC and hamate fractures (19). In the case of this report, the lateral radiograph showed only the fourth CMC joint dislocation, and the hook of the hamate fracture was identified by CT scan. Therefore, according to this study, it is recommended to use complementary techniques (such as CT scan) for the correct diagnosis. Emergency treatments include sedative and splint drugs; finally, ORIF techniques are usually used for definitive treatment and to ensure improved grip strength and prevention from post-traumatic arthritis $(15,18$, and 19). Roche et al. used Lie-binger mini-screws for fixation to treat a similar subject with this study. Besides, all normal clinical factors were reported in follow-up patients (20). 
North and Eaton used percutaneous K-wire in a similar case to fix and reduce the fracture, and the subsequent follow-up results were satisfactory (21). About the surgical technique, no particular preference has been observed in a certain method yet. For example, K-wires, palmar pins, mini lag screws, and Herbert screws have been used in similar cases, and the results were satisfactory (22-24). However, in the cases of hamate injury, which were anatomically considered as severely comminuted fractures, $\mathrm{K}$-wires are the preferred method (25). In this study, Kwire and ORIF techniques were used for treatment, and the patient's recovery was complete and satisfactory in 6 weeks.

\section{CONCLUSIONS}

According to our case report, it seems that a hamate fracture is often missed on initial presentation and initial X-ray, which emphasises the need for compulsive diagnostic evaluation such as CT imaging and careful follow-up. In fact, when there is a tenderness, and a reduced ROM on the base of fourth carpometacarpal joints, CT is helpful in a more accurate diagnosis.

\section{ACKNOWLEDGMENTS:}

The authors would like to thank Hashemi Nejad Hospital Emergency Department Staffs for providing the facilities of the study.

\section{CONFLICT OF INTEREST:}

There is no conflict of interest to be declared.

\section{AUTHORS' CONTRIBUTIONS:}

All authors contributed to this project and article equally. All authors read and approved the final manuscript.

\section{REFERENCES:}

1) Oni OO, Mackenny RP. Multiple dislocations of the carpometacarpal joints. Journal of hand surgery. 1986; 11(1): 47-8. doi: 10.1016/0266-7681(86)90010-0.

2) Pimpalnerkar AL, Fakih R, Thomas AP. Carpometacarpal dislocation producing transient motor neurapraxia of the ulnar nerve. Injury. 1997; 28(5-6): 397-400. doi: 10.1016/S0020-1383(96)00207-0.

3) Suh N, Ek ET, Wolfe SW. Carpal Fractures. The Journal of Hand Surgery. 2014; 39(4): 785-91. doi: 10.1016/j.jhsa.2013.10.030. PMid: 24679911.

4) Bernstein RA. Are hamate fractures common? Letter regarding" carpal fractures" article. The Journal of hand surgery. 2014; 39(11): 2344. doi: 10.1016/j.jhsa.2014.08.026. PMid: 25442748.

5) Boonstra R, Snellen J. A Case of hamate fracture with dislocation of the ring and little finger metacarpals imaged with three-dimensional computed tomography. Eur J Trauma. 2006; 32(3): 292-4. doi: 10.1007/s00068-006-5087-4.

6) Fakih RR, Fraser AM,Pimpalnerkar AL. Hamate fracture with dislocation of the ring and little finger metacarpals. Journal of Hand Surgery. 1998; 23(1): 96-7. doi: 10.1016/S0266-7681(98)80231-3.

7) Kerr HD. Hamate-metacarpal fracture dislocation. The Journal of emergency medicine. 1992; 10(5): 565-8. doi: 10.1016/0736-4679(92)90138-J.

8) Garcia-Elias M, Rossignani P, Cots M. Combined fracture of the hook of the hamate and palmar dislocation of the fifth carpometacarpal joint. Journal of hand surgery. 1996; 21(4): 446-50. doi: 10.1016/S0266-7681(96)80043-X.

9) Linscheid RL, Dobyns JH, Beabout JW, Bryan RS. Traumatic instability of the wrist. The Journal of Bone \& Joint Surgery. 1972; 54(8): 1612-32.

10) Posner MA, Ambrose L. Boxer's knuckle — dorsal capsular rupture of the metacarpophalangeal joint of a finger. The Journal of hand surgery. 1989; 14(2): 229-36. doi: 10.1016/0363-5023(89)90011-7.

11) Garcia-Elias M, Bishop A, Dobyns J, Cooney W, Linscheid R. Transcarpal carpometacarpal dislocations, excluding the thumb. The Journal of hand surgery. 1990; 15(4): 531-40. doi: 10.1016/S03635023(09)90011-9.

12) Milch H. Fracture of the hamate bone. J Bone Joint Surg. 1934; 16(459): 110-2.

13) Yoshida R, Shah MA, Patterson RM, Buford WL, Knighten J, Viegas SF. Anatomy and pathomechanics of ring and small finger carpometacarpal joint injuries. The Journal of hand surgery. 2003; 28(6): 1035-43. doi: 10.1016/S0363-5023(03)00373-3.

14) Howard FM. Ulnar-nerve palsy in wrist fractures. The Journal of Bone \& Joint Surgery. 1961; 43(8): 1197 201. 
15) Kerr HD. Hamate-metacarpal fracture dislocation. The Journal of emergency medicine. 1992; 10(5): $565-8$. doi: 10.1016/0736-4679(92)90138-J.

16) Stark HH, Jobe FW, Boyes JH, Ashworth C. Fracture of the hook of the hamate in athletes. The Journal of Bone \& Joint Surgery. 1977; 59(5): 575-82.

17) Terrono A, Ferenz C, Nalebuff E. Delayed diagnosis in non-union of the body of the hamate: a case report. Journal of Hand Surgery. 1989; 14(3): 329-31. doi: 10.1016/0266-7681(89)90096-X.

18) Cain JE, Shepler TR, Wilson MR. Hamatometacarpal fracture-dislocation: classification and treatment. The Journal of hand surgery. 1987; 12(5): 762-7. doi: 10.1016/S0363-5023(87)80064-3.

19) Bora FW, Didizian NH. The treatment of injuries to the carpometacarpal joint of the little finger. The Journal of Bone \& Joint Surgery. 1974; 56(7): 1459-63.

20) Roche S, Lenehan B, Street J, O'Sullivan M. Fourth metacarpal base fracture in association with coronal hamate fracture. Injury Extra. 2005; 36(8): 316-8. doi: 10.1016/j.injury.2004.12.058.

21) North ER, Eaton R. Volar dislocation of the fifth metacarpal. JBJS Case Connector. 1980; 1(4): 657-9.

22) Roth JH, de Lorenzi C. Displaced intra-articular coronal fracture of the body of the hamate treated with a Herbert screw. The Journal of hand surgery. 1988; 13(4): 619-21. doi: 10.1016/S0363-5023(88)80109-6.

23) Schwartz G. Displaced dorsal coronal fracture of the hamate. Orthopaedic review. 1989; $18(8)$ : 875-7. PMid: 2771436.

24) Van Schil P, De Smet C, Schoofs E. Fracture of the body of the hamate bone. Archives of orthopaedic and traumatic surgery. 1988; 107(3): 191-2. doi: 10.1007/BF00451604.

25) Jones R, Kutty S. Intra-articular fractures of the hamate. Injury. 1993; 24(4): 272-3. doi: 10.1016/00201383(93)90187-B. 